understand what is going on in the world of politics, but thinking about politics in a disciplined, systematic way is often not precisely what they expected. To make matters worse, most beginning students have only a minimal control over the vocabulary of our discipline. To take up the issues which interest students, to subject those issues to the rigorous analysis of political science, and to carry on a discourse in a language which the students have not yet internalized entails a great deal of negotiation and compromise.

Efforts to mainstream material on race, gender, and sexual orientation complicate the situation further. Students steeped in, and often fully committed to, the dominant culture fail to understand the complexities of minority status. Furthermore, although the purpose of mainstreaming is to move away from stereotypic thinking and to broaden the student's terms of reference, responding to the lacunae in some students' understanding of minority status runs the risk of reducing the minority students present in the classroom to the role of eavesdropper.

There are, as we all learned the hard way, a broad range of problems endemic to the very concept of mainstreaming. One obvious response is to strike an optimistic tone. Emphasizing an idealized and highly abstract future, free of conflict, provides students with a vi- sion, which they may come to accept as their personal goal.

In my opinion, however, political science is too earthbound to soar into the clouds. When it has transcended its boundaries, it has become dogmatic. Some of our students quickly see our efforts to inspire for what they are-wishful thinking - and quickly dismiss them as an unrealistic treatment of diversity. Others who are inspired may develop false expectations and illusions that often leave them especially vulnerable. In either case, the inspirational approach serves no useful purpose.

A second approach, and one that is far more popular, is to deal with the issues of diversity within the framework of domination/subordination. Such an approach certainly depicts the role of power in the study of politics, what it means to have power and the consequences of not possessing power. The scenario of domination/subordination in the areas of race and gender furnishes concrete examples of what happens when the powerless confront the powerful.

Despite these advantages, however, the domination/subordination approach has a fatal flaw: it represents the very embodiment of the double couplet. The subordinate group is, by definition, the victim and the problem. Even efforts to locate the subordinate group in a historical moment usually focus on a confrontation with the powerful, and if the group remains subordi- nate, in all probability it retains its status as problem/victim.

Thus, discussions of the first and second wave women's movements or the civil rights movement chronicle the struggle between the oppressor and the oppressed; in their very attempt to illustrate oppression they perpetuate it. As long as racism and sexism are treated as normal, they are reinforced.

What is the alternative? A celebration of African American women and their political accomplishments, such as Jewel Prestage has spoken to, is one possibility. It suggests an escape from the double couplet because it understands and accepts the implications of racial and sexual meanings and identities for action in specific historical settings. The changing historical character of racism and sexism must be moved to center stage, for as long as racism and sexism are treated as though they are normal, or eternal, or natural, the paradigm of a double couplet will remain in place.

\section{Reference \\ Gilroy, Paul G. 1984. There Ain't No Black in the Union Jack: The Cultural Politics of Race and Nation. London: Unwin Hyman.}

\section{About the Author \\ Marianne Githens is professor of political science at Goucher College.}

\title{
Mainstreaming Gender, Race, and Sexual Orientation in Teaching: A Student's Point of View
}

\author{
E. Joyce Parker, Washington, D.C.
}

In the early 1970 s when I was at York University, Toronto, Canada, I was always race conscious, as I still am. As a student for many years in the field of political science, I always brought my race into whatever I learned, asking at all times, "What does this mean for me?" I studied in order to understand the implication of the superstructure as it pertained to my race/ myself. I defined being Black in the same way as Malcolm X, not by the definitions used elsewhere. No matter what I read, what I studied, what I did, I reflected on it with the perspective that the White superstructure would always strive to make me a reject. And somehow I had to find ways to tell myself that I was not a reject but instead, as Malcolm suggested, the first, the best, the cream of the crop. With this philosophy, I came prepared to 
destroy in myself, and anywhere I saw it, the concept that White was superior. I was, in fact, prepared to prove the opposite.

What $I$ found instead in my political theory classes was that Locke, Rousseau, Marx . . . validated my beliefs. They did not change my basic belief structure; what they did instead was to offer me other tools of analysis. So now I talk about myself in many different ways. I have under my belt not only Malcolm X's view of what it is to be Black or White, but also the views of Locke, Rousseau, Marx and other social scientists.

I remember sitting in a first-year class when the teacher was discussing the issue of the Soviet/American conflict. I did not see any enmity, and I told my professor that the U.S. and U.S.S.R. would, by the twenty-first century, be allies. He asked, "What makes you think this?" I did not tell him; I merely said I could see the U.S. and the U.S.S.R. forming a new association as the Japanese and the Americans did after World War II. The class agreed that this was possible but pointed to the opposing views of these two countries, prepared to destroy each other even during a time of detente.

I did not say to the professor that I believed that the White people of the planet would come together to dominate and subjugate the Blacks as Malcolm suggested; but this was the premise from which I started. When I wrote a paper, I would not tell the teacher where my beliefs came from, but I would certainly shape my analysis to support them, and I would use historical references to promote my point of view. My real theme, White against Black, would not come through. Instead, I would discuss north/south conflicts, superpower status, industrialized/nonindustrialized conflicts, anything but race. I would not bring up the issue of race conflict as the reason for a U.S./U.S.S.R. joint effort.

The point here is that, whether we like it or not, race, gender, and sexual orientation will play a role in the individual student's thinking.
We will take the theories; we will look at them; and we will each use them. What each one thinks will be unique even though what we write and say will adhere to the required program.

If I had told my professor the true reason behind my belief that the U.S. and U.S.S.R. would become allies, perhaps he could have assisted me in the development of my thoughts. The teacher did not know my starting point and could not help me to develop my point of view. He could never know my true analysis; my presence still was not truly felt. With the mainstreaming of race, gender and sexual orientation in teaching, I hope the individual student's presence will be felt.

\section{About the Author}

E. Joyce Parker has a B.A. in political science from York University, Toronto, Canada and an M.A. in political science from the University of Toronto.

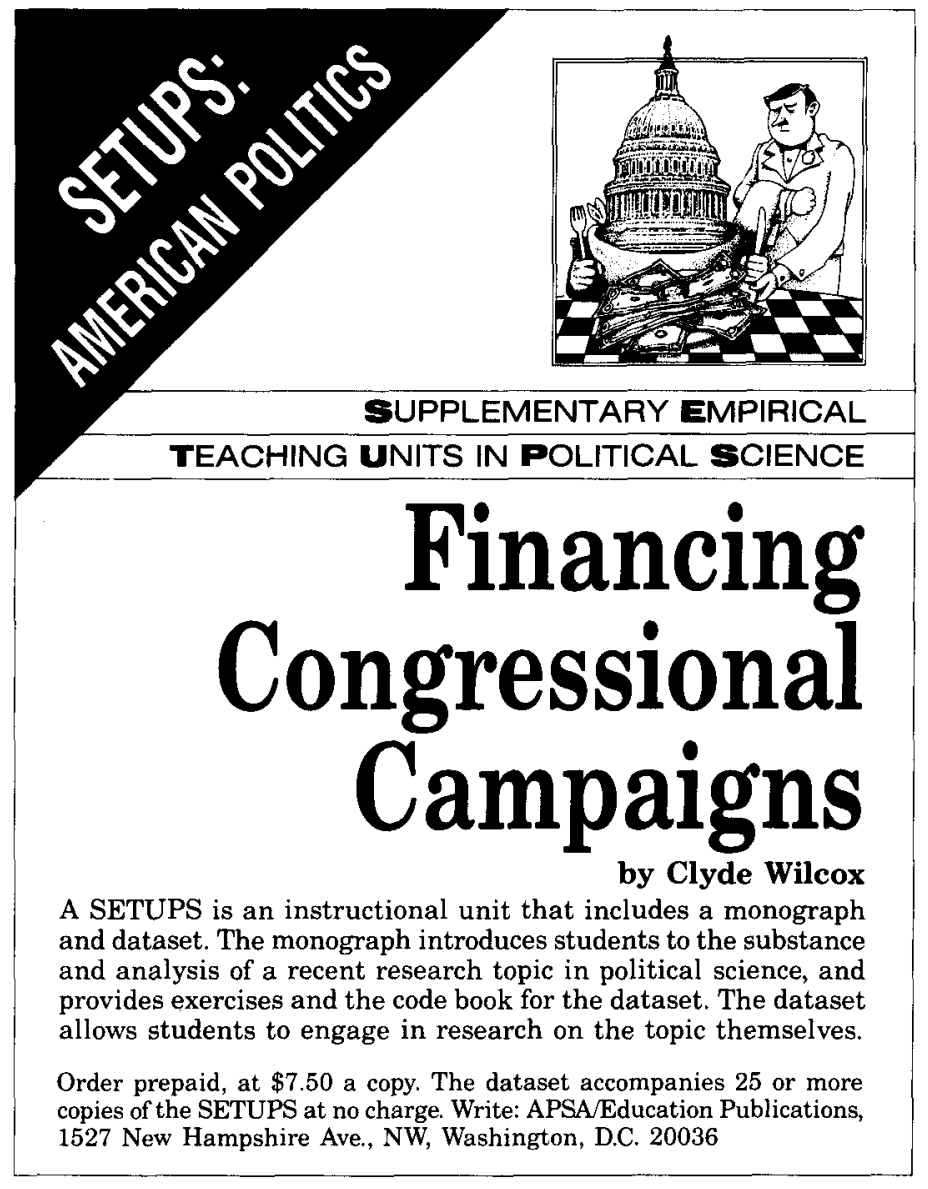

